\title{
Dentigerous Cyst- A Rare Case Report
}

\author{
Akanksha A. Auti1 ${ }^{1}$ Deepak K. Motwani², Neetu Y. Bhoplawad ${ }^{3}$ \\ ${ }^{1}$ Department of Oral and Maxillofacial Surgery, CSMSS Dental College, Aurangabad, Maharashtra, India. \\ ${ }^{2}$ Department of Oral and Maxillofacial Surgery, CSMSS Dental College, Aurangabad, Maharashtra, India. \\ ${ }^{3}$ Department of Oral and Maxillofacial Surgery, CSMSS Dental College, Aurangabad, Maharashtra, India.
}

\section{INTRODUCTION}

The second most frequently found cyst in the jaws is dentigerous cyst comprising of $14-20 \%$ cysts in the jaw. Mostly found in the mandible with male predilection.[1-4] This cyst is attached to the cervical margin of the tooth which is impacted. Reduced enamel epithelium proliferates after the enamel formation is complete which leads to the development of dentigerous cyst. These cysts enlarge as a result of accumulation of fluid between the crown of an impacted tooth and the reduced enamel epithelium. [5] When radiographs are taken to determine the reason for failure of a tooth to erupt, dentigerous cysts are usually discovered. They are usually unilocular, always radiolucent and large lesions occasionally show a scalloping multilocular pattern. ${ }^{[3,4,6,7]}$

The frequency of impaction is roughly the same as that of cyst formation for mandibular third molars. Maxillary third molars have higher frequency of impaction than cyst involvement, which suggest that this tooth has a much lower relative risk of developing a dentigerous cyst than its mandibular counterpart. ${ }^{[8]}$ Similarly, the risk of formation of cyst around the crowns of impacted mandibular first premolars, maxillary incisors, or mandibular second molars is very high, although the frequency of failure of eruption of these teeth is extremely low.[9] Dentigerous cysts are mostly painless but may attain large size with root resorption of teeth till it manifests clinically or radiographically. Treatment of cyst remains cystic enucleation and removal of suspected impacted tooth. Prognosis is good and recurrence is rare if removed completely.

Dentigerous cysts are seen most commonly in association with impacted maxillary and mandibular third molars and maxillary canines. Supernumerary teeth accounts only $5 \%$ of dentigerous cysts, of which mesiodens is the most common type. Initially such cysts remains completely painless unless infected, and discovered on routine radiographs. This paper presents a case of 35-year-old male patient with a dentigerous cyst associated with impacted right mandibular premolars and supernumerary teeth that caused painful swelling in the right lower buccal vestibule. The patient was treated surgically by enucleation of a dentigerous cyst in toto with surgical extraction of premolars and supernumerary teeth under local anaesthesia followed by primary wound closure.

\section{PRESENTATION OF CASE}

A 35-year-old male patient reported to Oral and Maxillofacial Department at C.S.M.S.S. Dental College and Hospital with a chief complaint of intraoral painful swelling in the lower right region which was present since 12 months. The chief complaint of the patient was pain with respect to 84 and 85 region which was cariously destructed since 15 - 20 days. Extraoral examination revealed no swelling. Intraoral examination revealed a swelling extending laterally from distal surface of mandibular right canine, inferiorly obliterating vestibule and superiorly up to the gingival margin [Fig. 1]. Slight tenderness was noticed on percussion with carious 84 and 85.
Corresponding Author:

Dr. Akanksha A. Auti,

Sai Shraddha Housing Society,

Shirdi-423109, Dist-Ahmednagar,

Maharashtra, India.

E-mail: autiakanksha9@gmail.com

DOI: $10.14260 /$ jemds/2019/867

Financial or Other Competing Interests: None.

How to Cite This Article:

Auti AA, Motwani DK, Bhoplawad NY. Dentigerous CYST- a rare case report. J. Evolution Med. Dent. Sci. 2019;8(52):40114013, DOI: 10.14260/jemds/2019/867

Submission 30-09-2019,

Peer Review 14-12-2019,

Acceptance 20-12-2019,

Published 30-12-2019. 
The panoramic radiograph [Fig. 2] showed radiolucency involving impacted 44, 45 and 2 supernumerary premolars which was large unilocular, well-circumscribed radiolucent lesion enveloping the unerupted premolars and two supernumerary teeth. Based on the aforementioned findings, it was provisionally diagnosed as dentigerous cyst with a differential diagnosis of radicular cyst or odontogenic keratocyst for which enucleation was considered as treatment option along with the removal of all unerupted teeth. Under local anaesthesia, maxillomandibular fixation using arch bars was done as a preventive measure for preventing pathologic fracture. Carious 84 and 85 were extracted and a full thickness mucoperiosteal flap was raised anteriorly from mandibular right lateral incisor to right second molar posteriorly [Fig. 3]. Surgical exposure of pathologic lesion was done [Fig. 4] and cystic lining was enucleated in toto along with the removal of all unerupted associated teeth [Fig. 5]. Platelet rich Fibrin (PRF) and decalcified freeze dried bone Allograft (DFDBA) (Osseograft) placed in the bony defect [Fig. 7] and mucoperiosteal flap was sutured with 3-0 black braided silk suture (BBSS) (Ethicon Mersilk). [Fig. 8] Cystic lining was sent for histopathology. Regular follow up was done for uneventful post-operative healing. On the basis of clinical, radiographic and histopathological findings [Fig. 9], the present case was diagnosed as dentigerous cyst involving the unerupted right mandibular premolars.

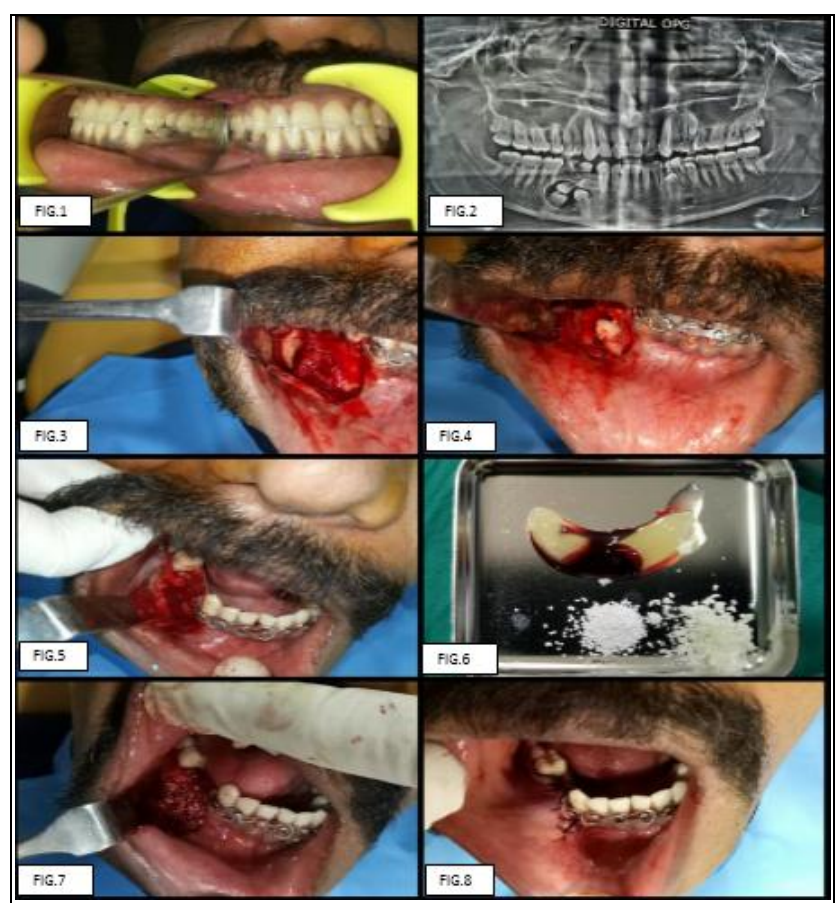

Fig. 1. Preoperative Photograph Showing Intraoral Swelling; Fig. 2: Preoperative Radiograph Showing Radiolucency with Sclerotic Border Involving 4 Premolars; Fig. 3: Reflection of Full Thickness

Mucoperiosteal Flap; Fig. 4: Exposure of Premolars; Fig. 5: Cyst Enucleation; Fig. 6: Platelet-Rich Fibrin and DFDBA; Fig. 7: PRF and DFDBA Placed in the Bony Defect; Fig. 8: Wound Closure Done Using 3O BBSS

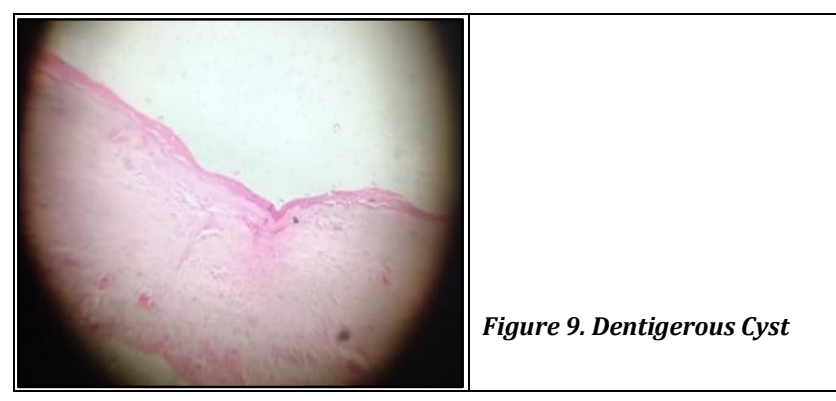

DISCUSSION

Dentigerous cysts of odontogenic origin are developmental cysts, which comprises of 14 to $24 \%$ of the cysts of jaw.[10,11] These can attain a large size with lesser or no complaints, early diagnosis and its removal is important to reduce morbidity. Literature suggests that dentigerous cysts occur more frequently during the second decade of life, ${ }^{[12,13]}$ and can also be found in children and adolescents. The ratio of dentigerous cysts in male and female patients is $1: 2 .{ }^{[14]}$ Whites are more prone to dentigerous cyst than blacks.[15] Dentigerous cysts are usually single, grow gradually, painless lesions that are found during routine radiographs incidentally, taken to identify a missing tooth in the arch. They can occur anywhere in the jaw but frequently seen in relation to impacted mandibular third molars followed by the maxillary canines and maxillary third molars.[15,16,17] Rarely these cysts become symptomatic when infected which cause erythema and swelling. These cysts are usually small in size but when large, leads to pathological fracture as a result of expansion and thinning of the cortex. ${ }^{[15,18]}$ The clinical presentation is relative to a dentigerous cyst, in our case it was associated with impacted mandibular premolars and supernumerary teeth.

Radiographic features are characterized by a well-defined radiolucency circumscribed by a sclerotic border, associated with the crown of an unerupted or impacted tooth. When infected the borders may be ill-defined. Rarely they may be found with a supernumerary tooth or an odontoma.[16,18] Follicular space greater than $4 \mathrm{~mm}$ is diagnosed to be a dentigerous cyst.[15] The cyst is classified according to its relation with the involved tooth crown as central, lateral and circumferential type. The most common is the central type which surrounds the crown. The lateral variant partially surrounds the crown and extends along the side of the root. The circumferential type presents both surrounding the crown and the root of the tooth involved.[16]

Histologically, 2 to 5 cell layers of cuboidal to flattened nonkeratinized epithelial cells lines the lumen. Forms keratin by metaplasia.[19] The connective tissue contains more collagen when inflamed. Chronic inflammatory cell infiltration is usually present. $[15,18]$ Treatment of dentigerous cysts is most commonly by Enucleation,[11] Marsupialization[20] and decompression of cyst by fenestration.[13] 
Enucleation along with removal of impacted tooth is the choice of treatment. Dentigerous cyst which are large are treated first with marsupialization followed by enucleation. Prognosis is good when the cyst is completely enucleated and recurrence rate is found to be rare. The epithelial lining has the pluripotential capacity cause of which these lesions may develop into ameloblastoma, squamous cell carcinoma and mucoepidermoid carcinoma.[15]

\section{REFERENCES}

[1] Assael LA. Surgical management of odontogenic cysts and tumors. In: Peterson LJ, Indresano TA, Marciani RD, et al, eds. Principles of oral and maxillofacial surgery. Vol 2. Philadelphia: JB Lippincott 1992:685-8.

[2] Neville BW, Damm DD, Allen CM, et al. Odontogenic cysts and tumors. In: Neville BW, Damm DD, Allen CM, et al, eds. Oral and maxillofacial pathology. Philadelphia: WB Saunders 1995:493-6.

[3] Regezi JA. Cyst and cyst-like lesions. In: Regezi JA, Sciubba J, Pogrel MA, eds. Atlas of oral and maxillofacial pathology. Philadelphia: WB Saunders 2000: p. 88.

[4] Martínez-Pérez D, Varela-Morales M. Conservative treatment of dentigerous cysts in children: a report of four cases. J Oral Maxillofac Surg 2001;59(3):331-3.

[5] Neville BW, Damm DD, Allen CM. Oral and maxillofacial pathology. $3^{\text {rd }}$ edn. St Louis: Saunders 2008:679-81.

[6] Dammer R, Niederdellmann H, Dammer P, et al. Conservative or radical treatment of keratocysts: a retrospective review. $\mathrm{Br} \mathrm{J}$ Oral Maxillofac Surg 1997;35(1):46-8.

[7] Aguiló L, Gandía JL. Dentigerous cyst of mandibular second premolar in a five-year-old girl, related to a nonvital primary molar removed one year earlier: a case report. J Clin Pediatr Dent. 1998;22(2):155-8.

[8] Benn A, Altini M. Dentigerous cysts of inflammatory origin: a clinicopathologic study. Oral Surg Oral Med Oral Pathol 1996;81(2):203-9.
[9] Shear M. Cysts of the jaws: recent advances. J Oral Pathol 1985;14(1):43-59.

[10] Regezi AJ, Sciubba JJ. Cysts of the oral region in oral pathology: clinical pathologic correlations. $3^{\text {rd }}$ edn. Philadelphia: WB Saunders 1999:288-321.

[11] Rubin DM, Vendrenne D, Portnof JE. Orthodontically guided eruption of mandibular second premolar following enucleation of an inflammatory cyst: a case report. J Clin Pediatr Den 2002;27(1):19-23.

[12] Arotiba JT, Lawoyin JO, Obiechina AE. Pattern of occurrence of odontogenic cysts in Nigerians. East Afr Med J 1998;75(11):664-6.

[13] Ziccardi VB, Eggleston TI, Scheinder RE. Using fenestration technique to treat a large dentigerous cyst. J Am Dent Assoc 1997;128(2):201-5.

[14] Ustuner E, Fitoz S, Atasoy C, et al. Bilateral maxillary dentigerous cysts: a case report. Oral Surg Oral Med Oral Pathol Oral Radiol Endod 2003;95(5):632-5.

[15] Sumita M, Vineet R, Karen B, et al. Non-syndromic bilateral dentigerous cysts of mandibular premolars: a rare case and review of literature. Hong Kong Dent J 2006;3(2):129-33.

[16] Shah N, Thuau H, Beale T. Spontaneous regression of bilateral dentigerous cysts associated with impacted mandibular third molars. Br Dent J 2002;192(2):75-6.

[17] Kumar Mohapatra P, Joshi N. Conservative management of a dentigerous cyst associated with an impacted mandibular second premolar in mixed dentition: a case report. J Dent Res Dent Clin Dent Prospects 2009;3(3):98102.

[18] Aziz SR, Dourmas MA, Roser SM, et al. Inferior alveolar nerve paresthesia associated with a mandibular dentigerous cyst. J Oral Maxillofac Surg 2002;60(4):4579.

[19] Shear M. Dentigerous cyst. In: Shear M, ed. Cysts of the oral regions. Mumbai: Varghese Publishing House 1996.

[20] Murakami A, Kawabata K, Suzuki A, et al. Eruption of an impacted second premolar after marsupialization of a large dentigerous cyst: case report. Pediatr Dent 1995;17(5):372-4. 